\title{
Contribution of nucleus raphe magnus to thermoregulation
}

\author{
Masoumeh Kourosh Arami ${ }^{1 *}$ iD, Alireza Komaki², Shahriar Gharibzadeh ${ }^{3}$ \\ 1. Department of Neuroscience, School of Advanced Technologies in Medicine, Iran University of Medical Sciences, Tehran, \\ Iran \\ 2. Neurophysiology Research Center, Hamedan University of Medical Sciences, Hamedan, Iran \\ 3. Institute for Cognitive and Brain Sciences, Shahid Beheshti University, Tehran, Iran
}

\begin{abstract}
Thermoregulation is the maintenance of the core body temperature. The regulation of body temperature is one of the most important functions of the nervous system. Nucleus raphe magnus, as a central circuit coordinates the homeostatic response and maintains body temperature during environmental temperature challenges and adjusts body temperature during the inflammatory response and behavioral states and in response to decreasing energy homeostasis. Our aim in this review is the understanding of thermoregulation by raphe magnus in mammals. This review summarizes the basic concepts of thermoregulation and subsequently assesses the physiological responses to cold stress, including skin blood flow control, sweating, sympathetic-derived cutaneous vasoconstriction and peripheral thermoregulatory control in brown adipose tissue.
\end{abstract}

\section{Keywords:}

Nucleus raphe magnus;

Thermoregulation

* Corresponding author:

M. Kourosh-Arami

Email:

kourosharami.m@iums.ac.ir

Tel: $+98(21) 86704788$

Received 8 November 2019; Received in revised form 13 March 2020; Accepted 23 March 2020

http://dx.doi.org/10.32598/ppj.24.3.20

\section{Introduction}

The hypothalamus is the central coordinating center for thermoregulation. Evidence shows that the preoptic anterior hypothalamus is the most central area for autonomic temperature regulation. The inputs to the hypothalamus come from peripheral and central thermoreceptors (Tansey and Johnson, 2015). The raphe premotor neurons cause cutaneous vasoconstriction through excitatory glutamatergic and serotonergic connections to spinal preganglionic neurons. Cold exposure activates a direct preoptic-toraphe excitatory pathway (Romanovsky, 2018). Nucleus raphe magnus (NRM) is situated in the caudal pons and the most rostral part of the medulla.
NRM that possesses the greatest percentage of cells responding to cutaneous temperature (Dickenson, 1977) acts as an essential component of the thermoregulatory region in the central nervous system of rats (Asahina et al., 2003) and manages cutaneous blood flow (Berner et al., 1999; Korsak and Gilbey, 2004). Subclasses of medullary raphespinal neurons appear to function as a key brain stem temperature control center, regulating the activity of the peripheral sympathetic nerves innervating brown fat and the tail circulation in rats (Nalivaiko and Blessing, 2002). Previous studies in rabbits show that inhibition of neuronal function in the medullary region entirely prevents cutaneous vasoconstriction initiated 
by nociceptive stimulation (Blessing and Nalivaiko, 2000). Inhibition of neuronal function in this region reverses cutaneous vasoconstriction induced by cooling the animal (Blessing, 2003). Thus, the raphe region contains neurons whose activation leads to cutaneous vasoconstriction. Evidence demonstrated that the central area of the raphe is needed for the control of rat tail blood flow (Asahina et al., 2003; Rathner and McAllen, 1999). Neurons in the medullary raphe region constitute excitatory neurons that could be categorized as a class of sympathetic premotor neurons for the regulation of body temperature (Nakamura et al., 2004). Bulbospinal presympathetic neurons in the rostral medullary raphe region seem to regulate cutaneous blood flow responses arising as part of the regulation of body temperature (Blessing, 2003). In hypothermia, blood is redirected from the skin to other organs and the loss of heat in rats is regulated by blood flow under sympathetic control, through an elaborate system of arteriovenous anastomoses of tail (Malakouti et al., 2008). In addition, excitation of neurons in the raphe region causes vasoconstriction in the skin blood vessels without intensely influencing arterial pressure and change in the mesenteric bed flow (Blessing and Nalivaiko, 2000; Nalivaiko and Blessing, 2002).

The mechanisms of thermal control for the cutaneous circulation have been thoroughly reviewed (Holowatz et al., 2010; Johnson et al., 2011). Nitric oxide (NO) as a major second messenger in the central and peripheral nervous systems contributes in thermoregulation. NO operates as a central activator of heat defense mechanisms and is synthesized in all mesencephalic raphe nuclei cells. In our previous study, we evaluated the role of $\mathrm{NO}$ on thermoregulatory action of NRM neurons (Arami et al., 2015). The weight of medullary raphe in managing the rat tail blood flow (TBF) has been confirmed by (i) augmentation of tail sympathetic nerve activity after chemically activation of raphe neurons through glutamate microinjections, (ii) revealing the sympathetic premotor neurons in medullar raphe nuclei after tracer injections into the tail artery and (iii), enhancement of the expression of Fos immunoreactivity, primarily in the raphe, during hypothermia (Malakouti et al., 2008).

In this review, we will discuss the basic perceptions of thermoregulation in skin and therefore assess the physiological responses to hypothermia, including skin blood flow control, sweating and shivering. Also, we will discuss the effect of raphe magnus on cutaneous blood flow control in mammals. Furthermore, we will assess the role of $\mathrm{NO}$ in this thermoregulatory effect of NRM. Moreover, we will focus on the sympathetic-derived cutaneous vasoconstriction and peripheral thermoregulatory control in brown adipose tissue (BAT).

\section{Cutaneous blood flow control}

The sequential activities of daily life are organized in a manner that results in differential involvement of different bodily organs at any given time, with consequent regional variations in metabolic rate (Blessing, 2003). Nutrient supply is mediated via a corresponding patterning of the amount of blood flowing to particular organs at a particular time, with control occurring via combinations of local, hormonal and neural factors. In some cases, the physiological function of an organ requires blood flow independently of metabolic needs. The secretion of the saliva for example, requires increased blood flow to the salivary glands because the water in saliva is derived from blood. These non-metabolic requirements for increased blood flow are likely to occur in relation to environmental events that elicit particular behavior patterns. In such situations, neural control from the central nervous system is especially important (Blessing, 2003).

The skin, as a bodily organ, obviously has its own metabolism, with its own nutrient blood flow requirements. However, blood flow to the skin is regulated in proportion to two major non-metabolic requirements, both demonstrating the fact that the skin is the margin between the individual and the external environment. The healthy functioning of the whole organism requires that the temperature of bodily organs, especially the brain, be maintained at a suitable level. Net heat transport between the individual and the external environment depends on the amount of blood flowing through the skin so that in most mammals' cutaneous blood flow is regulated as an intrinsic component of body temperature control. The second non-metabolic factor affecting cutaneous blood flow is sympathetically-mediated vigorous vasoconstriction initiated when the individual perceives a potentially dangerous environmental event. Apparently, this response shows the fact that the skin is a region of the body particularly vulnerable 
to injury because as the boundary between the individual and the external environment, it bears the initial brunt of any physical attack (Blessing, 2003). To minimize blood loss from consequential injury, blood must be kept away from the skin. The shortterm (over minutes) metabolic requirements of the skin are not vital. Thus, during the physical attack, or in response to a painful ("nociceptive") stimulus, blood can be diverted from the cutaneous bed and diverted to bodily organs with more urgent metabolic requirements. The complexity of the central nervous system allows a response to revealing a stimulus signifying a possibility of dangerous environmental event (one type of "salient" event). Detection of such an event starts an integrated emotional response with both somatic and autonomic components (LeDoux, 1995) that include noticeable constriction of the cutaneous vascular bed (Yu and Blessing, 1997). In mammals, and particularly in primates, the individual's concept of a possibly dangerous event has extended, so that fear and anxiety resulting from the perception of psychosocial threats, without the actual experience of pain or physical attack may also provoke cutaneous vasoconstriction. It is only in recent years that specific details have emerged concerning the central neural pathways involved in sympathetically mediated regulation of cutaneous blood flow that occurs as part of body temperature control and as part of emotionally mediated cutaneous vasoconstriction (Blessing, 2003).

\section{Thermoregulation through the tail circulation in rodents}

In the rat, $\sim 20 \%$ of total body heat-loss takes place by sympathetically- mediated increases in blood flow through its tail (Smith et al., 1998). The rat's tail is well suited to function as a heat-loss organ since it lacks fur, is well vascularized and has a large surface area to volume ratio. In fact, rats can scatter their basal metabolic heat creation through their tails. Following whole body warming and exercise, an intense enhancement in blood flow through the tail happens that functions to cool the animal. This effect is dependent upon central pathways that block the sympathetic outflow to the tail artery which feeds an elaborate system of cutaneous arteriovenous anastomoses. As blood flow raises, skin temperature increases above the ambient temperature, permitting heat loss (Smith et al., 1998).
The tail artery of the rat is directed by a simple peripheral sympathetic system including only vasoconstrictor fibers; numerous premotor cell groups regulate this sympathetic outflow. The inputs occur in local spinal neurons, sympathetic propriospinal neurons as well as cell groups found throughout the brainstem, hypothalamus and preoptic region (Smith et al., 1998).

\section{Sympathetic premotor neurons in medullary raphe regions mediating thermoregulatory functions}

Premotor neurons of sympathetic neurons directly innervate sympathetic preganglionic neurons (SPNs) in the intermediolateral cell column of the thoracic spinal cord and many of these premotor neurons are restricted in the medulla oblongata. The rostral ventrolateral medulla comprises premotor neurons that regulate the cardiovascular conditions, whereas rostral medullary raphe regions are a candidate source of sympathetic premotor neurons for thermoregulatory functions. These medullary raphe areas include putative glutamatergic neurons and that these neurons directly control thermoregulatory SPNs. Those neurons that express vesicular glutamate transporter 3 (VGLUT3) were placed in the rat medullary raphe regions, including the raphe magnus and rostral raphe pallidus nuclei, and generally lacked serotonin immunoreactivity. VGLUT3-expressing neurons in the medullary raphe regions comprise excitatory neurons that could be categorized as a novel group of sympathetic premotor neurons for thermoregulatory functions (Nakamura et al., 2004).

SPNs, in turn, make outputs leading to the stimulation of peripheral effector organs. These bulbospinal premotor pathways are thought to mediate the regulation of blood circulation, body temperature, metabolism and other diverse homeostatic functions. The focus of many studies on sympathetic premotor control has been brought into the regulation of the cardiovascular system (Nakamura et al., 2004). Of the known cardiovascular-regulating brain regions, the rostral ventrolateral medulla (RVLM) is the most established region to contain sympathetic premotor neurons that play a crucial role in the control of arterial blood pressure. However, RVLM premotor activity scarcely contributes to the control of other effector organs, such as the pupil, nictitating 
membrane, gut, BAT and rat tail artery (Nakamura et al., 2004).

The rostral medullary raphe regions consisting of the rostral part of the raphe pallidus nucleus and the NRM have been considered as a possible sympathetic premotor region involved in thermoregulation. Stimulation of these regions raised the sympathetic activity of thermoregulatory effector organs, such as rat interscapular BAT, rat tail artery and rabbit ear pinna blood vessels (Blessing and Nalivaiko, 2000). Furthermore, neurons in these raphe areas were activated by cold exposure and central administration of prostaglandin-E2, an endogenous pyrogenic mediator (Nakamura et al., 2005), and inhibition of these regions eliminated sympathetic BAT thermogenesis and fever triggered by central prostaglandin-E2 administration (Morrison, 2003; Oka, 2004). In addition, these raphe regions contain intermediolateral-projecting neurons, a part of which were activated by cold exposure (Rathner et al., 2001). However, by lack of any appropriate signs to categorize thermoregulatory neurons in these raphe regions, functional neuroanatomical characterization of these neurons is not recognized. Moreover, such signs would directly confirm the existence of raphe sympathetic premotor neurons serving thermoregulatory functions (Nakamura et al., 2004).

Activation of NRM neurons evokes sympathoexcitatory alterations in blood pressure, heart rate and thermoregulation (Cao and Morrison, 2003; Nason Jr and Mason, 2004). Some serotonergic NRM cells project directly to preganglionic sympathetic neurons in the intermediolateral cell column and may influence sympathetic tone via this connection (Mason et al., 2007). Within the thoracic spinal cord, serotonin depolarizes preganglionic sympathetic neurons while serotonin receptor antagonists block the pressor response evoked by medullary raphe stimulation (Mason et al., 2007). A serotonin receptor agonist that apparently inhibits serotonergic cells blocks leptin-induced activation of BAT, implying that serotonergic NRM cells mediate food-induced thermogenesis, a process that is accompanied by increases of blood pressure (Cao and Morrison, 2003). Serotonergic NRM cells could control cardiovascular tone or thermoregulation through both a direct excitation of preganglionic sympathetic neurons and an indirect inhibitory effect mediated by inhibition of sympathoexcitatory cells in the ventrolateral medulla (Mason et al., 2007).

\section{NO-mediated skin blood flow regulation by NRM}

$\mathrm{NO}$ is synthesized from L-arginine by a family of enzymes, the NO synthases (NOS) of which three types have been identified: the neuronal (nNOS), the endothelial (eNOS) and the inducible (iNOS) forms (Nucci et al., 2004). Capillary blood flow per se is considered to be principally regulated by local factors, of which NO appears to be the most powerful. Nitric oxide, due to its short half-life of only a few seconds, is believed to be a severely local regulating factor skin blood flow (Peltonen and Pyörnilä, 2004). NO plays a significant role in causing the dorsal column stimulation-induced enhancement in rat cutaneous hind paw blood flow (Croom et al., 1997). It is reported that nitric oxide is involved in central cardiovascular regulation, baroreflex modulation (Kourosh Arami et al., 2006).

NRM is one of the cellular groups of the brainstem that includes NO synthase (Nucci et al., 2004). Previous reports demonstrate that NRM is involved in thermoregulation. In support of this concept, it has been revealed that there is an association between changes in firing rates of cells in the NRM and the peripheral thermal stimulus. Furthermore, blockade of NRM electrical activity or particular inhibition of the NRM neurons influences both peripherally and centrally elicited thermoregulatory responses. $\mathrm{NO}$ as both a second messenger and neurotransmitter has been involved in an extremely varied range of physiological functions. Studies suggest that $\mathrm{NO}$ is involved in the control of breathing and thermoregulatory responses during hypoxia. As to hypoxic anapyrexia, the administration of NOS inhibitors produces a slight increase in basal body temperature (Nucci et al., 2004). NO operates as a central activator of heat defense mechanisms and is synthesized in all mesencephalic raphe nuclei cells. In our previous study, we found that the administration of NO donor into NRM effectively prevented thermal vasoconstriction of rat tail vessels in response to hypothermia. In conclusion, NO modulates cutaneous blood flow in the NRM in rats during hypothermia (Arami et al., 2015).

We found that administration of L-NAME into raphe prevented the blood flow increase by glutamate during hypothermia (Arami et al., 2015). During 
postnatal development, some glutamatergic synapses first contain NMDA receptors (Arami et al., 2016; Kourosh Arami et al., 2011), which mainly yield hyperpolarization and inhibitory effects (D'yakonova, 2000). Synchronized application of glutamate and nitroprusside, which is a NO donor, however, established an opposite effect, as cells responded to glutamate with depolarization and excitation. These results demonstrated that $\mathrm{NO}$ is involved in transforming inhibitory responses to glutamate into excitatory ones and that this effect may be mediated by NMDA-type receptors (D'yakonova, 2000).

\section{Medullary raphe neurons facilitate BAT activation}

Recent evidence suggests that the medullary raphe is important to heat production during cold protection and fever. Placing rats in a cold environment results in c-fos-labeled cells scattered throughout the NRM, raphe pallidus and the adjacent reticular nuclei (Cano et al., 2003; Martínez et al., 2001). Furthermore, it is reported that exposure of rats to cold temperatures leads to an augmentation in Fos expression immunoreactivity, which is concentrated in the raphe (Tanaka et al., 2002). Frequent Fos-positive cells were detected in many brain areas following cold exposure and such alterations may disclose the cellular adaptation of the thermogenic responsive neurons in the rat brain to hypothermia (Miyata et al., 1995). It has shown that bicuculline microinjection into areas all over the ventral medulla including the raphe pallidus (RP), NRM and the lateral reticular nuclei activates BAT (Nason Jr and Mason, 2004). GABA-mediated inhibition of raphe neurons regulates sympathetic outflow to BAT (Morrison et al., 1999). Therefore, GABA through activation of sympathetic outflow may activate BAT.

Medullary raphe inactivation inhibits BAT activation (Morrison, 2003; Morrison, 2001; Nakamura, 2011). NRM-RP neurons project to the intermediolateral cell column, where targeted cells comprise preganglionic sympathetic neurons, as well as to the superficial dorsal horn, where thermoreceptors terminate (Nason and Mason, 2006). Furthermore, NRM-RP neurons project oligosynaptically to BAT tissue (Cano et al., 2003). BAT thermogenesis is regulated synergistically by the sympathetic nervous system and thyroid hormones (Ortiga-Carvalho et al., 2011). The mammal is equipped with numerous hierarchical thermoneutral zone comparators. In this model, the spinal cord is the most basic place of thermoregulatory integration but can only protect a comparatively broad (several degrees) thermoneutral zone and descending modulation from the brainstem and hypothalamus increasingly narrows the thermoneutral range. In fact, the spinal cord maintains body temperature, but within a large thermoneutral zone (Nason and Mason, 2006). Medullary raphe lesions cause changes in the thermoneutral zone (Nason and Mason, 2006). Raphe cells may adjust the excitability of preganglionic sympathetic neurons through connections to preganglionic cells, to premotoneurons in the intermediate gray or to thermoreceptive cells in the superficial dorsal horn that are themselves presynaptic to preganglionic sympathetic neurons (Nason and Mason, 2006). Because electrical stimulation in the raphe modifies the responses of thermoreceptive neurons in the dorsal horn, NRM-RP may modulate BAT activation through effects on thermoreceptive afferents to local preganglionic sympathetic neurons (Nason and Mason, 2006).

Disinhibition of NRM-RP cells raises BAT nerve activity from approximately nothing to continuous, near maximal activity (Nason and Mason, 2006). On the contrary medullary raphe inactivation blocks the raise of BAT activity evoked by cold or pyrogen administration (Morrison 2003; Morrison et al., 2008; Nakamura, 2011). These dramatic results may derive from a modulatory change, as is the case for the most robust examples of heat production and heat loss. After pyrogen administration, neutral temperatures are interpreted as cold. In the case of hot flashes, a small increase in core temperature that does not elicit any vasomotor reaction in asymptomatic women causes noteworthy cutaneous vasodilation, followed by sweating and the sensation of being hot in symptomatic women (Freedman and Subramanian, 2005). Consequently, a change in the interpretation of a steady, unchanging temperature can make large thermoeffector reactions. It is hence not surprising that the activation or inactivation of a modulatory control on BAT-controlling circuits can either produce BAT activation or block increases in BAT activity.

BAT is the core site of non-shivering thermogenesis (Ballinger and Andrews, 2018) in hibernators. Hibernation as a seasonal event is preceded by a 
reduction transition phase that body weight augmented (MacCannell et al., 2017) and body temperature diminishes (Sheriff et al., 2012). One of the neuropeptides that has effects on BAT and involves in thermoregulation is orexin (Kuwaki, 2015). Orexin neuropeptides that are produced in the lateral part of the hypothalamus area activate postsynaptic neurons via two G-protein coupled receptors (Babasafari et al., 2019; Rezaei et al., 2020). Administration of orexin $A$ increases the firing rate of the sympathetic nerves to interscapular BAT, accompanied with a rise in BAT and colonic temperatures (Messina et al., 2014). One explanation for relation of orexin with thermoregulation may be the dense existence of orexin fibers in the raphe magnus (Peyron et al., 1998).

\section{The raphe magnus regulates sweat secretion}

In the human palm/sole, mental or physical stimuli provoke an augmentation in sweat secretion and a decline in skin blood flow. Though, the central pathways of these responses are unclear. Sweat secretion and skin blood flow in the cat footpad are measured by electrically stimulating the raphe. Stimulation of the rostral raphe magnus/pallidus caused a decline in skin blood flow without affecting sweat secretion. Stimulation of the mid to caudal raphe magnus/pallidus increased in both sweat secretion and skin blood flow. The raphe magnus/pallidus may play a crucial role in skin vasomotor and sudomotor responses in the cat footpad (Asahina et al., 2007).

The hairless skin of the cat footpad is homologous to the human palm, which is innervated by three types of sympathetic postganglionic fibers that supply the blood vessels and sweat glands. Of all the human body skin, only the palm and sole sweat in response to mental or physical stimuli, such as mental arithmetic, deep breathing and isotonic exercise which decreases in skin blood flow and enhances sweat secretion in the palm and sole concurrently. These two reactions, skin vasomotor reflex and sympathetic sweat response reveal particular sympathetic innervation of the palm and sole that are useful for clinically evaluating skin sympathetic function (Asahina et al., 2007). Nevertheless, the central pathways that justify the skin vasomotor reflex and sympathetic sweat response remain unclear. Previous experimental studies on skin vasomotor function have examined the ear pinnae of rabbits and the tails of rats, where electrical stimulation to the medullary raphe magnus/pallidus provoked skin blood flow diminution or augmented tail sympathetic activity, respectively. Additionally, electrical stimulation of the ponto-medullary reticular formation in cats provoked electrodermal responses (Asahina et al., 2007). Skin vasomotor and sudomotor functions are all essential in thermoregulation and the raphe magnus/pallidus participates in thermoregulation by control of the skin blood flow and BAT metabolism (Asahina et al., 2007).

Electrical stimulation of the rostral raphe magnus/pallidus reduced skin flow blood, while stimulation of the mid to caudal raphe magnus/pallidus caused sweat secretion and skin blood flow rise in the forepaw pads of decerebrate cats. These findings demonstrate that the raphe magnus/pallidus has an important role in the regulation of sweat secretion and skin blood flow in the hairless skin of forepaw pads in cats, which are homologous to the hairless skin of palms in humans, where the skin vasomotor reflex and sympathetic sweat response are clinically obtained. Skin blood flow in the cat footpad may be related to thermoregulation (Asahina et al., 2007). The raphe magnus/pallidus is an important brainstem relay center for thermoregulatory skin vasomotor function because stimulation of the raphe magnus/pallidus reduced skin blood flow in rat tails and rabbit ear pinnae (Asahina et al., 2007). Inhibition of that region promoted skin sympathetic (vasoconstrictor) nerve activity diminution in rat tails. However, palms are distinct from other areas of human skin, in that palmar blood flow responds to non-thermal stimuli, as observed in skin vasomotor reflex. In humans, the major function of sweating is the regulation of body temperature (thermoregulatory sweating). In cats, sweating, which is seen only in the hairless skin (footpad), does not appear to participate in thermoregulation. This system may be activated during specific behaviors (such as the defense reaction), and activation of sweat glands may be important in keeping the hairless skin flexible for optimal sensory discrimination and for adhesion to the ground. In humans, sweating on the palm/sole (emotional sweating) is also independent of ambient temperature, and it is caused by emotional stimuli, mental stress or physiological stimuli. Central circuitry 


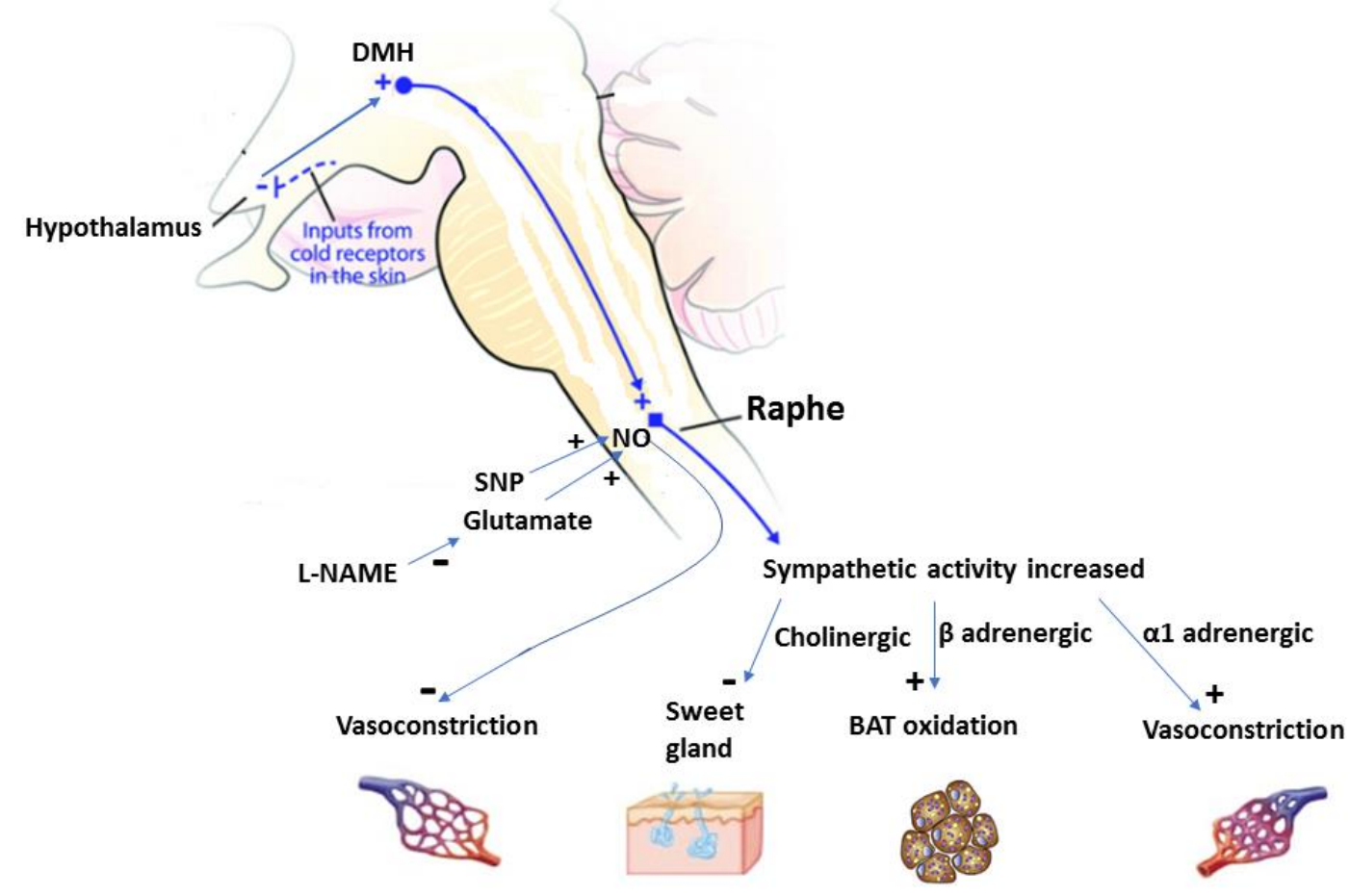

Fig.1. Central circuitry mediating the response to cold. The hypothalamus neurons are inhibited by inputs from cold receptors in the skin. Hypothalamic neurons tonically inhibit cold-responsive neurons of the dorsomedial nucleus of the hypothalamus $(\mathrm{DMH})$ and raphe neurons. Cold exposure results in decrease in hypothalamic activity and disinhibition of $\mathrm{DMH}$ and raphe neurons that initiate sympathetic neurons activation and so responses for heat conservation (skin vasoconstriction) or production (shivering or nonshivering thermogenesis), brown adipose tissue (BAT) activation, sweet gland inactivation. Microinjection of sodium nitroprusside (SNP) inhibits vasoconstriction through increment of nitric oxide (NO) release in nucleus raphe magnus. Also, L-NAME as an inhibitor of NO synthase prevents the excitatory effect of glutamate in nucleus raphe magnus.

regulating the response to cold is shown in Figure 1.

There is a likelihood that neurons in the mid to caudal raphe magnus/pallidus might exert an excitatory drive on the skin vasodilator neurons; there has been considerable controversy regarding the presence or absence of a specific population of sympathetic vasodilator neurons projecting to the cutaneous vasculature. Another possibility is that skin vasodilatation might accompany sweating, because acetylcholine and vasodilator neuropeptides (e.g. calcitonin gene-related peptide, vasoactive intestinal peptide), which are co-localized in sudomotor fibers, make skin vasodilation (Asahina et al., 2007).

In summary, this study shows that NRM is an important area involved in skin blood flow regulation to control body temperature. NRM by affecting on sympathetic nerves activates BAT and constricts skin blood vessels.

\section{Acknowledgments}

We would like to thank Tarbiat Modares University and Iran University of Medical Sciences for their support to carry out this research.

\section{Conflict of interest}

The authors declare no conflict of interest.

\section{References}

Arami MK, Mirnajafi-Zade J, Komaki A, Amiri M, Mehrpooya $S$, Jahanshahi $A$, et al. Nitric oxide in the nucleus raphe magnus modulates cutaneous blood flow in rats during hypothermia. Iran J Basic Med Sci 2015; 18: 989-992.

Arami MK, Hajizadeh S, Semnanian S. Postnatal development changes in excitatory synaptic activity in the rat locus coeruleus neurons. Brain Res 2016; 1648: 365-71. https://doi.org/10.1016/j.brainres.2016.07.036

Asahina M, Kikkawa Y, Suzuki A, Hattori T. Cutaneous sympathetic function in patients with multiple system atrophy. Clin Auton Res 2003; 13: 91-5. https://doi.org/ 10.1007/s10286-003-0072-z

Asahina M, Sakakibara R, Liu Z, Ito T, Yamanaka Y, Nakazawa $K$, et al. The raphe magnus/pallidus regulates sweat secretion and skin vasodilation of the cat forepaw pad: a preliminary electrical stimulation 
study. Neurosci Lett 2007; 415: 283-7. https://doi.org/ 10.1016/j.neulet.2007.01.033

Babasafari M, Kourosharami M, Behman J, Farhadi M, Komaki A. Alteration of phospholipase $\mathrm{C}$ expression in rat visual cortical neurons by chronic blockade of orexin receptor 1. Int J Pept Res Ther 2019; 1-7. https://doi.org/10.1007/s10989-019-09943-y

Ballinger MA, Andrews MT. Nature's fat-burning machine: brown adipose tissue in a hibernating mammal. J Exp Biol 2018; 221: jeb162586. https://doi.org/10.1242/ jeb.162586

Berner NJ, Grahn DA, Heller HC. 8-OH-DPAT-sensitive neurons in the nucleus raphe magnus modulate thermoregulatory output in rats. Brain Res 1999; 831: 155-64. https://doi.org/10.1016/S0006-8993(99)01426-2

Blessing WW, Nalivaiko E. Regional blood flow and nociceptive stimuli in rabbits: patterning by medullary raphe, not ventrolateral medulla. J Physiol 2000; 524: 279-92. https://doi.org/10.1111/j.1469-7793.2000.t01-200279.x

Blessing WW. Lower brainstem pathways regulating sympathetically mediated changes in cutaneous blood flow. Cell Mol Neurobiol 2003; 23: 527-38. https://doi.org/10.1023/A:1025020029037

Cano G, Passerin AM, Schiltz JC, Card JP, Morrison SF, Sved AF. Anatomical substrates for the central control of sympathetic outflow to interscapular adipose tissue during cold exposure. J Comp Neurol 2003; 460: 30326. https://doi.org/10.1002/cne.10643

Cao WH, Morrison SF. Disinhibition of rostral raphe pallidus neurons increases cardiac sympathetic nerve activity and heart rate. Brain Res 2003; 980: 1-10. https://doi.org/10.1016/S0006-8993(03)02981-0

Croom JE, Foreman RD, Chandler MJ, Koss MC, Barron $\mathrm{KW}$. Role of nitric oxide in cutaneous blood flow increases in the rat hindpaw during dorsal column stimulation. Neurosurgery 1997; 40: 565-71. https://doi. org/10.1097/00006123-199703000-00027

D'yakonova TL. NO-producing compounds transform neuron responses to glutamate. Neurosci Behav Physiol 2000; 30: 153-9. https://doi.org/10.1007/ BF02463153

Dickenson $\mathrm{AH}$. Specific responses of rat raphé neurones to skin temperature. J Physiol 1977; 273: 277-93. https://doi.org/10.1113/jphysiol.1977.sp012094

Freedman RR, Subramanian M. Effects of symptomatic status and the menstrual cycle on hot flash-related thermoregulatory parameters. Menopause 2005; 12: 156-9. https://doi.org/10.1097/00042192-20051202000009

Holowatz LA, Thompson-Torgerson C, Kenney WL. Aging and the control of human skin blood flow. Front Biosci 2010; 15: 718. https://doi.org/10.2741/3642

Johnson JM, Minson CT, Kellogg Jr DL. Cutaneous vasodilator and vasoconstrictor mechanisms in temperature regulation. Compr Physiol 2011; 4: 33-89. https://doi.org/10.1002/cphy.c130015

Korsak A, Gilbey MP. Rostral ventromedial medulla and the control of cutaneous vasoconstrictor activity following icv prostaglandin E1. Neuroscience 2004; 124: 709-17. https://doi.org/10.1016/j.neuroscience.2003.12.019

Kourosh Arami M, Sarihi A, Behzadi G, Amiri I, Malacoti SM, Vahabian M. The effect of nucleus tractus solitarius nitric oxidergic neurons on blood pressure in diabetic rats. Iran Biomed J 2006; 10: 15-19.

Kourosh Arami M, Semnanian S, Javan M, Hajizadeh S, Sarihi A. Postnatal developmental alterations in the locus coeruleus neuronal fast excitatory postsynaptic currents mediated by ionotropic glutamate receptors of rat. Physiol Pharmacol 2011; 14: 338-48.

Kuwaki T. Thermoregulation under pressure: a role for orexin neurons. Temperature 2015; 2: 379-91. https://doi.org/10.1080/23328940.2015.1066921

LeDoux JE. Emotion: clues from the brain. Annu Rev Psychol 1995; 46: 209-35. https://doi.org/10.1146/ annurev.ps.46.020195.001233

MacCannell A, Sinclair K, Friesen-Waldner L, McKenzie CA, Staples JF. Water-fat MRI in a hibernator reveals seasonal growth of white and brown adipose tissue without cold exposure. J Comp Physiol B 2017; 187: 759-67. https://doi.org/10.1007/s00360-017-1075-8

Malakouti SM, Kourosh Arami M, Sarihi A, Hajizadeh S, Behzadi G, Shahidi S, et al. Reversible inactivation and excitation of nucleus raphe magnus can modulate tail blood flow of male wistar rats in response to hypothermia. Iran Biomed J 2008; 12: 237-240.

Martínez V, Wang L, Taché Y. Central TRH receptor 1 antisense blocks cold-induced gastric emptying but not brain c-Fos induction. Peptides 2001; 22: 81-90. https://doi.org/10.1016/S0196-9781(00)00359-4

Mason P, Gao K, Genzen JR. Serotonergic raphe magnus cell discharge reflects ongoing autonomic and respiratory activities. J Neurophysiol 2007; 98: 1919-27. https://doi.org/10.1152/jn.00813.2007

Messina G, Chieffi S, Monda M. Orexin A exerts more thermogenic than orexinergic functions. PeerJ PrePrints 2014. https://doi.org/10.7287/peerj.preprints.392

Miyata S, Ishiyama M, Shido O, Nakashima T, Shibata M, Kiyohara T. Central mechanism of neural activation with cold acclimation of rats using Fos immunohistochemistry. Neurosci Res 1995; 22: 209-18. https://doi.org/10.1016/0168-0102(95)00900-X

Morrison SF. Raphe pallidus neurons mediate prostaglandin E2-evoked increases in brown adipose tissue thermogenesis. Neurosci 2003; 121: 17-24. https://doi.org/10.1016/S0306-4522(03)00363-4

Morrison SF. Differential regulation of brown adipose and splanchnic sympathetic outflows in rat: roles of raphe and rostral ventrolateral medulla neurons. Clin Exp Pharmacol Physiol 2001; 28: 138-43. https://doi.org/10.1046/j.1440-1681.2001.03406.x

Morrison SF, Nakamura K, Madden CJ. Central control of thermogenesis in mammals. Exp Physiol 2008; 93: 77397. https://doi.org/10.1113/expphysiol.2007.041848

Morrison SF, Sved AF, Passerin AM. GABA-mediated inhibition of raphe pallidus neurons regulates sympathetic outflow to brown adipose tissue. Am J Physiol Regul Integr Comp Physiol 1999; 276: R290-7. 
https://doi.org/10.1152/ajpregu.1999.276.2.R290

Nakamura K. Central circuitries for body temperature regulation and fever. Am J Physiol Regul Integr Comp Physiol 2011; 301: R1207-28. https://doi.org/10.1152/ ajpregu.00109.2011

Nakamura K, Matsumura K, Hübschle T, Nakamura Y, Hioki $\mathrm{H}$, Fujiyama $\mathrm{F}$, et al. Identification of sympathetic premotor neurons in medullary raphe regions mediating fever and other thermoregulatory functions. J Neurosci 2004; 24: 5370-80. https://doi.org/10.1523/ JNEUROSCI.1219-04.2004

Nakamura Y, Nakamura K, Matsumura K, Kobayashi S, Kaneko T, Morrison SF. Direct pyrogenic input from prostaglandin EP3 receptor-expressing preoptic neurons to the dorsomedial hypothalamus. Eur J Neurosci 2005; 22: 3137-46. https://doi.org/10.1111/ j.1460-9568.2005.04515.x

Nalivaiko E, Blessing WW. Potential role of medullary raphe-spinal neurons in cutaneous vasoconstriction: an in vivo electrophysiological study. J Neurophysiol 2002; 87: 901-11. https://doi.org/10.1152/jn.00221.2001

Nason Jr MW, Mason P. Modulation of sympathetic and somatomotor function by the ventromedial medulla. $J$ Neurophysiol 2004; 92: 510-22. https://doi.org/10.1152/ jn.00089.2004

Nason MW, Mason P. Medullary raphe neurons facilitate brown adipose tissue activation. J Neurosci 2006; 26 : 1190-8. https://doi.org/10.1523/JNEUROSCI.4707-05. 2006

Nucci TB, Branco LG, Gargaglioni LH. Nitric oxide pathway in the nucleus raphe magnus modulates hypoxic ventilatory response but not anapyrexia in rats. Brain Res 2004; 1017: 39-45. https://doi.org/10.1016/ j.brainres.2004.05.011

Oka T. Prostaglandin E2 as a mediator of fever: the role of prostaglandin E (EP) receptors. Front Biosci 2004; 9: 3046-57. https://doi.org/10.2741/1458

Ortiga-Carvalho T, Chiamolera M, Pazos-Moura C, Wondisford F. Hypothalamus-pituitary-thyroid axis. Compr Physiol 2011; 6: 1387-428. https://doi.org/ 10.1002/cphy.c150027

Peltonen LM, Pyörnilä A. Local action of exogenous nitric oxide (NO) on the skin blood flow of rock pigeons
(Columba livia) is affected by acclimation and skin site. $\mathrm{J}$ Exp Biol 2004; 207: 2611-9. https://doi.org/ 10.1242/jeb.01051

Peyron C, Tighe DK, Van Den Pol AN, De Lecea L, Heller HC, Sutcliffe JG, et al. Neurons containing hypocretin (orexin) project to multiple neuronal systems. J Neurosci 1998; 18: 9996-10015. https://doi.org/10.1523/ JNEUROSCI.18-23-09996.1998

Rathner J, Owens NC, McAllen RM. Cold-activated raphéspinal neurons in rats. J Physiol 2001; 535: 841-54. https://doi.org/10.1111/j.1469-7793.2001.t01-1-00841.x

Rathner JA, McAllen RM. Differential control of sympathetic drive to the rat tail artery and kidney by medullary premotor cell groups. Brain Res 1999; 834: 196-9. https://doi.org/10.1016/S0006-8993(99)01568-1

Rezaei Z, Kourosh-Arami M, Azizi H, Semnanian S. Orexin type-1 receptor inhibition in the rat lateral paragigantocellularis nucleus attenuates development of morphine dependence. Neurosci Lett 2020; 134875. https://doi.org/10.1016/j.neulet.2020.134875

Romanovsky AA. Thermoregulation Part 1: from basic neuroscience to clinical neurology. Elsevier, 2018.

Sheriff MJ, Williams CT, Kenagy G, Buck CL, Barnes BM. Thermoregulatory changes anticipate hibernation onset by 45 days: data from free-living arctic ground squirrels. J Comp Physiol B 2012; 182: 841-7. https://doi.org/10.1007/s00360-012-0661-z

Smith JE, Jansen AS, Gilbey MP, Loewy AD. CNS cell groups projecting to sympathetic outflow of tail artery: neural circuits involved in heat loss in the rat. Brain Res 1998; 786: 153-64. https://doi.org/10.1016/S00068993(97)01437-6

Tanaka M, Nagashima K, McAllen ZM, Kanosue K. Role of the medullary raphe in thermoregulatory vasomotor control in rats. J Physiol 2002; 540: 657-64. https://doi.org/10.1113/jphysiol.2001.012989

Tansey EA, Johnson CD. Recent advances in thermoregulation. Adv Physiol Educ 2015; 39: 139-48. https://doi.org/10.1152/advan.00126.2014

$\mathrm{Yu} \mathrm{YH}$, Blessing WW. Acute increases in forebrain blood flow during alerting responses in conscious rabbits. Brain Res 1997; 767: 1-7. https://doi.org/10.1016/ S0006-8993(97)00439-3 